"This is an Accepted Manuscript of an article published by Taylor \& Francis in Medical Teacher on 27 September 2016, available online:

http://www.tandfonline.com/10.1080/0142159X.2016.1210114 ." 
Using a meta-ethnographic approach to explore the nature of facilitation and teaching approaches employed in interprofessional education

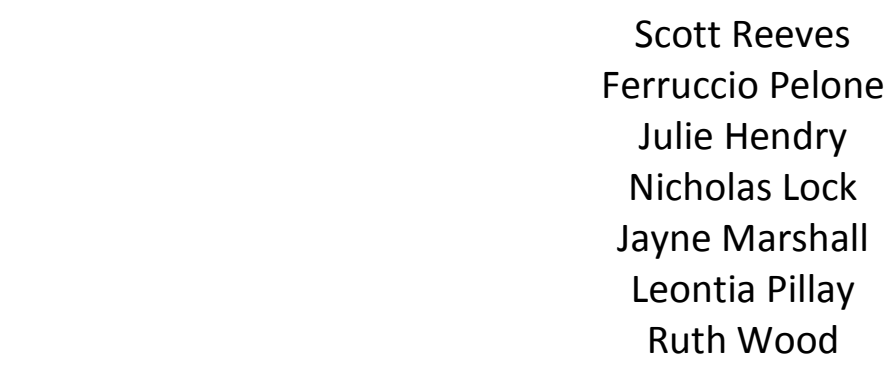

Faculty of Health, Social Care and Education, Kingston University and St George's, University of London, UK

Corresponding author

Professor Scott Reeves

Kingston University \& St George's, University of London

St George's Hospital, Cranmer Terrace, London, SW17 OBE, UK

s.reeves@sgul.kingston.ac.uk 


\title{
Using a meta-ethnographic approach to explore the nature of facilitation and teaching approaches employed in interprofessional education
}

\begin{abstract}
Background: Interprofessional facilitators and teachers are regarded as central to the effective delivery of interprofessional education (IPE). As the IPE literature continues to expand, most studies have focused on reporting learner outcomes, with little attention paid to IPE facilitation. However, a number of studies have recently emerged reporting on this phenomenon.
\end{abstract}

Aim: To present a synthesis of qualitative evidence on the facilitation of IPE, using a metaethnographic approach.

Methods: Electronic databases and journals were searched for the past 10 years. Of the 2,164 abstracts initially found, 94 full papers were reviewed, and subsequently 12 papers were included. Two researchers independently completed each step in the review process. The quality of these papers was assessed using a modified critical appraisal checklist.

Results: Seven key concepts embedded in the included studies were synthesised into three main factors which provided an insight into the nature of IPE facilitation. Specifically, the synthesis found that IPE facilitation is influenced by 'contextual characteristics'; 'facilitator experiences' and 'use of different facilitation strategies'.

Conclusions: IPE facilitation is a complex activity affected by contextual, experiential and pedagogical factors. Further research is needed to explore the effects of these factors in IPE.

Keywords: Interprofessional education; Interprofessional facilitation; teaching, learning; metaethnography

\section{Introduction}

Interprofessional education (IPE) is as an activity that occurs when two or more professions learn together on an interactive basis to improve collaboration and the quality of care (Barr et al., 2005). The rationale for the development of IPE is that learning together can enhance interprofessional practice which, in turn, can improve the delivery of health and social care services as well as enhance patient safety practices (Barr et al., 2005; World Health Organization, 2010). Encouragingly, evidence for the effects of IPE has been growing over the past few years. As a result, an increasing amount of IPE scoping and systematic reviews have synthesised the evidence base. Collectively, these reviews have indicated that this form of education can help to nurture interprofessional collaboration (Hammick et al., 2007; Reeves et al., 2016) and improve healthcare outcomes in several fields such as mental health (Pauzé \& Reeves 2010; Curran et al., 2012), delirium care (Sockalingam et al., 2014), diabetes care and domestic violence management (Reeves et al., 2013). 
While there has been a growth of IPE reviews reporting the effectiveness of this type of education on participants' collaborative competence and ability to deliver safe and effective care (Brandt et al., 2014; Lawlis et al., 2014; Reeves et al., 2013, 2016; Sunguya et al., 2014), little attention has been placed on the facilitation/teaching processes employed by individuals who deliver IPE. In addition, while there has been a growth of qualitative IPE studies, there has been no attempt to synthesise this type of research to assess the nature of the growing qualitative evidence base. This paper presents the findings from a meta-ethnography that synthesised available qualitative research to understand the nature of IPE facilitation.

\section{Background}

The role of the IPE facilitator (also referred to as teacher, mentor, preceptor, supervisor) has long been seen as fundamental in the literature (e.g. Cleghorn \& Baker 2000, Howkins \& Bray 2008). IPE facilitators are regarded as key in setting the learning climate and also creating a comfortable, positive and collaborative learning environment (e.g. classroom, practice placement, online learning). To date, the IPE literature has offered a series of possible attributes required for staff to facilitate interprofessional learning in an effective manner. These include experience of collaborative practice, conflict resolution skills, flexibility, confidence and a good sense of humour (Holland 2002; Freeth et al., 2005; Howkins \& Bray 2008). However, it has been found that most IPE facilitators often do not have the required attributes to successfully facilitate interprofessional collaborative learning (Reeves 2000; Steinert 2005). Consequently, Madden et al. (2006) have recommended that a range of faculty/staff development opportunities should be provided to IPE facilitators. While such activities can help prepare facilitators for their IPE work, it has been argued that faculty/staff development needs to be regularly offered to maintain facilitation competence Howkins \& Bray 2008). It has also been argued that IPE facilitators need to be effective role models for interprofessional collaboration (Selle et al., 2008). Indeed, a report by Lindblom et al. (2007) revealed that students stressed the importance of interprofessional role modelling to help them learn how to collaborate more effectively in clinical settings. Given the importance of the IPE facilitator role and the growth of the IPE literature, combined with a lack of attention to qualitative synthesis, a meta-ethnography was undertaken to synthesise available qualitative research in the IPE literature.

\section{Methods}

Mindful of a range of methodological debates related to meta-ethnography as this approach evolves (Atkins et al., 2008; Toye et al., 2014), the synthesis reported in this paper was framed by an established meta-ethnographic approach (Noblit \& Hare, 1988) and also applied a pre-existing protocol (Reeves et al., 2015).

The synthesis was guided by the following objectives:

1. To synthesise the available qualitative research related to the involvement of staff who facilitate IPE in health and social care. 
2. To investigate the potential influence of IPE contextual factors (e.g. professional mix, space and time constraints) and teacher characteristics (e.g. expertise and attitudes, perception of learners) on the IPE they facilitate.

3. To identify any gaps in the IPE evidence, and suggest a future agenda for research.

\section{Inclusion criteria}

For the purposes of this review, IPE was defined as an activity that occurs "when members (or students) of two or more professions learn with, from and about one another to improve collaboration and the quality of care" (Barr et al., 2005). Specifically, this review focused on studies reporting the delivery of IPE by teachers (also termed facilitators, mentors, preceptors and coaches) to learners.

Studies which met the following criteria were included in the review:

1. They were defined as an IPE study according to the definition presented above.

2. Teachers were involved in the delivery of IPE to learners from health and/or social care backgrounds.

3. The studies were qualitative in nature, such as, phenomenological studies, ethnographic studies, grounded theory studies or case studies (Hancock et al., 2002).

\section{Search strategy}

Nine electronic databases were systematically searched for relevant peer-reviewed papers: Applied Social Sciences Index and Abstracts (ASSIA), British Education Index (BEI), CINAHL Plus, EMBASE, ERIC, Healthcare Management Information Consortium (HMIC), MEDLINE and PsycINFO. A MEDLINE search strategy was formulated in to address the review objectives and the inclusion criteria (Reeves et al., 2015), when necessary this was adjusted to implement on other bibliographic databases. Search results were limited to the past 10 years and to papers written in English.

Additional papers were obtained searching the reference lists of included studies and also from hand searching the last ten years of two journals, namely Medical Teacher and Journal of Interprofessional Care that publish the largest number of IPE research.

\section{Study selection}

The selection process was conducted in two stages - title/abstract screening followed by full-text paper screening. After duplicates were removed, two reviewers from the team independently screened all titles and abstracts produced from the searches. Studies were not considered further when their abstract or their title (when the abstract was unavailable) clearly pointed out that: (1) the focus was not IPE; (2) the study was a systematic review, a quantitative study, a commentary and/or had not been peer-reviewed. 
Full-text articles of any relevant titles/abstracts were obtained and screened with reasons for exclusion added. At this stage of the screening process, one reviewer independently scanned the reference list of the included studies for potentially eligible articles that were not identified through the electronic searches.

Both the abstract and the full-text screening were performed in parallel by two members of the review team working in pairs, with discrepancies resolved by a third reviewer. Furthermore, each stage was guided by a check-list to ensure consistency among the review team in applying the eligibility criteria.

Study selection, including reasons for exclusion, is summarised in Figure 1. In the final stage of the selection process a total of 11 papers were excluded because they either did not focus on facilitators' experiences in delivering IPE $(n=6)$ or they evaluated learners' perceptions of IPE facilitation $(n=5)$ rather than focusing on the facilitators' own perspectives as defined in the inclusion criteria. Twelve studies (Cooper \& Spencer-Dawe., 2006; Lindqvist \& Reeves., 2007; Rees \& Johnson., 2007; Anderson \& Thorpe., 2010; Carlson et al., 2011; Egan-Lee et al., 2011; van Soeren et al., 2011; Chipchase et al., 2012; Clouder et al., 2012; Hanna et al., 2013; Evans et al., 2014; Jakobsen \& Hansen., 2014) met the inclusion criteria and were included in the synthesis.

\section{INSERT FIGURE 1 ABOUT HERE}

\section{Data abstraction and synthesis}

For each included study, two reviewers independently extracted the following information:

- Details of study characteristics - study objectives, methodology, sample, study setting and the year of publication;

- Results information - key themes or concepts identified in the studies (distinguishing between first and second order interpretation);

- Context information - details about the IPE teaching and learning processes;

- Study quality - criteria for assessing the methodological quality of included studies were based on the Critical Appraisal Skills Programme (CASP) tool (CASP 2006). This tool was slightly modified so that each of the items collectively provided an aggregate score which indicated study rigor. These criteria covered issues such as, appropriateness of the research design to address the study aims, appropriateness of sampling/recruitment procedures and appropriateness of data collected.

The approach to synthesising the included studies (aggregating information, re-interpretion, developing a synthesis) was informed by the approach developed by Noblit \& Hare (1988), and adapted by Britten et al. (2002). In doing so, the included papers were read and re-read by the review team to gain a detailed understanding of their contents. From this work second order 
interpretations (i.e. original author interpretations of data) were collated to identify key concepts. This informed a subsequent stage of analysis in which the review team's own concepts and second order interpretations were compared and contrasted in order to develop a series of synthesised third-order interpretations (key factors) based on the evidence in the included papers.

\section{Findings}

Summary and context of included articles

The characteristics of the 12 included studies are presented in Table 1. The geographic setting for the studies varied with five studies from the United Kingdom, three from Canada and one each from Australia, Denmark, Sweden and Vietnam. Within these studies IPE was delivered in a classroom context (4 studies), a practice-based setting ( 2 studies), a mixture of classroom and practice settings ( 2 studies), via an online methods ( 3 studies) or simulated learning environment (1 study).

With regard to the facilitation approach employed, most of the studies described IPE activities coled by two facilitators (Cooper \& Spencer-Dawe., 2006; Jakobsen \& Hansen., 2014; Hanna et al., 2013; Anderson \& Thorpe., 2010; van Soeren et al., 2011) or single facilitators (Lindqvist \& Reeves., 2007; Carlson et al., 2011; Egan-Lee et al., 2011; Evans et al., 2014; Rees \& Johnson., 2007). Clouder et al., (2012) in contrast, reported on the experiences of peer facilitators in an online IPE context, while one study was focused on the role of the clinical supervisor in facilitating IPE in practice placements (Chipchase et al., 2012).

The number of facilitators involved in the included studies ranged from four (Chipchase et al., 2012) to 58 (Anderson \& Thorpe., 2010). The facilitators were from a range of professional backgrounds, including, nursing ( 6 studies), physiotherapy ( 5 studies), occupational therapy (4 studies), medicine and social work (3 studies) and speech pathology ( 2 studies).

\section{INSERT TABLE 1 ABOUT HERE}

\section{Study methods and quality appraisal}

The 12 qualitative studies included in this review, involved six case studies, three phenomenology studies, one ethnography, one participatory action research study as well as a study that described employing a 'qualitative approach' (see Table 1). A variety of methods were used to collect study data. Focus groups were most common used (Anderson \& Thorpe, 2010; Carlson et al., 2011; Chipchase et al., 2012; Cooper \& Spencer-Dawe., 2006; Hanna et al., 2013; Jakobsen \& Hansen, 2014; Lindqvist \& Reeves, 2007; Rees \& Johnson, 2007; van Soeren et al., 2011), followed by individual interviews (Anderson \& Thorpe, 2010; Carlson et al., 2011; Chipchase et al., 2012; Cooper \& Spencer-Dawe, 2006; Egan-Lee et al., 2011; Hanna et al., 2013; Clouder et al., 2012; Rees \& Johnson, 2007), observations (Carlson et al., 2011; Hanna et al., 2013; van Soeren et al., 2011), written reflections (Cooper \& Spencer-Dawe, 2006; Jakobsen \& Hansen, 2014; Clouder et 
al., 2012) and telephone interviews (Evans et al., 2014; Lindqvist \& Reeves, 2007). In general, most studies gathered two or more types of qualitative data (Table 1).

In terms of methodological quality, all studies clearly described the research question, the methods of data collection and analysis (see Table 2). Only three studies considered researcher reflexivity (Carlson et al., 2011; Egan-Lee et al., 2011; Rees \& Johnson, 2007). Most of the studies failed to provide any information on the sampling strategy (Clouder et al., 2012); those that did generally used a simple convenience sample (Chipchase et al., 2012; Cooper \& Spencer-Dawe, 2006; Jakobsen \& Hansen, 2014; Rees \& Johnson., 2007; van Soeren et al., 2011). Based on the modified critical appraisal tool (CASP 2006), it was found that the included studies were generally robust in nature.

\section{INSERT TABLE 2 ABOUT HERE}

\section{Key findings from the synthesis}

The synthesis generated seven key concepts which were linked to the second order interpretation embedded in the 12 selected studies. These concepts were synthesised into three main factors (third-order interpretations). As a result of this synthesis, IPE facilitation was found to be mainly influenced by the following factors: contextual characteristics; facilitator experiences and use of different facilitation strategies (See Table 3). Below, details are provided relating to how these three factors affect the nature of IPE facilitation.

\section{INSERT TABLE 3 ABOUT HERE}

In relation to the 'contextual characteristics' factor, the synthesis revealed that logistical/organisational and information technology issues contributed to facilitators' ability to facilitate IPE. In terms of logistical/organisational issues, the synthesis indicated that IPE facilitation was an additional activity which needed to be managed on top of facilitators' normal profession-specific workloads. However, for facilitators engaged with interprofessional e-learning the asynchronous aspect of their role ensured flexibility as it could be fitted around professionspecific workloads (Anderson \& Thorpe, 2010; Evans et al., 2014). The synthesis also revealed that a lack of resources and organisational support could impede facilitators' work (Anderson \& Thorpe, 2010). In addition, large cohorts of students created difficulties for facilitators with regards to impeding interaction between learners (Rees \& Johnson, 2007). In respect of the effect of e-learning technologies, the synthesis indicated non-verbal communication between facilitators and learners could undermine learning processes (Hanna et al., 2013). Technical problems were also identified as a potential issue as they impacted on the delivery mode. However it was reported that skilled facilitators used any technological problems they encountered as a positive learning experience to encourage students to problem solve solutions on a collaborative basis (Evans et al., 2014). 
The following three issues, facilitator preparation and support, collaborating and co-facilitating and using IPE facilitation as a professional development opportunity, contributed to the 'facilitator experiences' factor. It was found that initial preparation and on-going support for facilitators was required in order to meet the demands of this complex role (Rees \& Johnson, 2007, Lindqvist \& Reeves, 2007, Evans et al., 2014; Egan-Lee et al., 2011). Furthermore, it was reported that regular opportunities should be offered for facilitators to share knowledge, experiences and ideas (Rees \& Johnson., 2007, Lindqvist \& Reeves, 2007). With regards to the second issue, it was found that cofacilitation was key to developing collaboration between IPE facilitators (Hanna et al., 2013) and regular planning and discussion between facilitators could promote formal and informal collaboration (Jakobsen \& Hansen., 2014). Co-facilitation could ensure learners' different professional experiences could be connected which in turn offered more learning opportunities (van Soeren et al., 2011). Where a more experienced IPE facilitator supported a new facilitator, cofacilitation was regarded as effective in providing direct learning experiences for a neophyte (Egan-Lee et al., 2011). It was also reported that service users who co-facilitated IPE along with professional facilitators could provide positive, enjoyable and valuable IPE experiences for students (Cooper \& Spencer-Dawe., 2006). The use of IPE facilitation as a professional development opportunity was found to be an important element as it allowed facilitators to enhance their interprofessional facilitation knowledge and skills (Egan-Lee et al 2011; Clouder et al., 2012; Evans et al., 2014). Engagement in IPE also provided facilitators with opportunities to form new relationships with colleagues and students from other professions which could further promote their knowledge of each other's roles (Anderson \& Thorpe., 2010) as well as offer opportunities to consider changes to their own clinical and professional practice (Cooper \& Spencer-Dawe, 2006).

In relation to the 'different facilitation strategies' factor, employing differing interprofessional teaching approaches and using interprofessional approaches and experiences to enrich the learning, contributed to facilitators' ability to facilitate IPE. When employing differing interprofessional teaching approaches, the synthesis identified that IPE facilitators employed a range of facilitation techniques to encourage effective student learning. These focused on the following: employing learner and teacher-centric approaches (van Soeren et al., 2011); using shared reflection (Carlson et al., 2011); providing effective instruction before the IPE and offering feedback after the learning (van Soeren et al., 2011; Clouder et al., 2012); exploring different knowledge domains and professional responsibilities (Carlson et al., 2011); and displaying enthusiasm, humour and empathy to help promote collaborative learning (Lindqvist \& Reeves., 2007).

Regarding the issue of using interprofessional approaches and experiences to enrich the learning, it was found that IPE facilitators employed a number of techniques, which included, supporting collaboration by ensuring learners took patient care decisions by mutual consent of all team 
members (Carlson et al., 2011), offering regular interprofessional briefing sessions (Chipchase et al., 2012) and drawing on their previous experiences of interprofessional collaboration to inform their facilitation work with learners (Lindqvist \& Reeves., 2007).

\section{Discussion}

As presented above, the synthesis of the qualitative IPE facilitation literature indicated that this type of activity is influenced by three main factors: the nature of the context in which the IPE is delivered can either support or impede the facilitators work; the nature of the facilitators' experiences in relation to, for example, preparation, on-going support and co-facilitation; and the use of different facilitation strategies can enhance the nature of IPE experience for learners.

Based on these findings, one can argue that when designing future IPE experiences, curricular developers need to be mindful of these facilitation factors in the recruitment, preparation and ongoing support of facilitators, as attention to each factor can improve the overall experience of teaching and learning for both facilitators and leaners. Specifically, the synthesis revealed a need for initial professional development for all new facilitators to help them cope with the complex role of facilitating IPE. Furthermore, the use of co-facilitation (between two facilitators from different professional backgrounds) was found as a means of enhancing the quality of interprofessional teaching and learning. In addition, it was reported that engaging service users in the IPE facilitation process can provide additional value to the IPE learning experience. The use of different approaches to interprofessional teaching (e.g. offering a learner-centric approach, providing students with opportunities for shared reflection, displaying enthusiasm, humour and empathy) was also reported to affect the IPE learning experiences. The synthesis also identified that interprofessional e-learning could be facilitated in ways which could provide stimulating learning experiences, albeit was dependent on effective technology and the facilitator's ability to overcome the challenge in engaging all students.

As noted above, the tool used in this synthesis to assess the methodological quality of the 12 included studies (CASP 2006) revealed that this empirical work could be generally regarded as rigorous in nature. However, the synthesis of the studies revealed that facilitation occurred in a range of different types of learning contexts, specifically, classrooms, practice placements, simulation and e-learning. Further research is needed to explore each of these learning contexts in more depth to identify issues of convergence and divergence between them in order to develop a better appreciation of the approaches IPE facilitators adopt to effectively engage with learners. Further research is also needed to explore the nature of co-facilitation as well as the use of peer facilitators in the classroom, the clinical supervisors' role and service users in facilitating IPE in practice placements. In addition, as most of the included studies relied on self-report data in the form of interviews or focus groups (data that generate perceptions about facilitation practices rather than actual practices) more effort is needed to undertake observational studies of IPE facilitation. In doing so, one can generate studies that provide directly observed accounts of the 
nature of facilitators' work which would form a rigorous evidence base from which to improve IPE facilitation practice. Finally, as the IPE facilitation literature grows, it is recommended that an update of this synthesis is undertaken to understand how newer research into IPE facilitation complements the findings reported in this paper, or provides new insights into the nature of IPE facilitation.

There are a number of strengths related to this synthesis. These include: the prospective registration with the Prospero review database (Reeves et al., 2015), the use of an established approach to undertaking meta-ethnographic work (Noblit \& Hare., 1988; Britten et al., 2002); a broad search covering eight electronic databases as well as journal hand searches and search of the reference lists of included papers. As a result, this review has provided a comprehensive account of qualitative research into IPE facilitation. Nevertheless, while best practices for reviewing and synthesising qualitative evidence were employed, there are inevitably limitations in this work. The search was limited by excluding the grey literature and including studies only published in English. As a result, a small number of potential studies may have been missed. In addition, only studies published in the past 10 years were included in this synthesis, excluding the findings from any earlier work. It is also acknowledged that there a more general bias within the literature for publishing research that reports positive results which can mean that IPE facilitation studies reporting more negative findings may struggle for publication.

\section{Concluding comments}

This synthesis of 12 qualitative studies of IPE facilitation indicated seven key concepts linked to second-order interpretations that were embedded in this work. These concepts were synthesised into three third-order interpretations which suggested that IPE facilitation is influenced by contextual characteristics, facilitator experiences and use of different facilitation strategies. In undertaking this synthesis it is anticipated that this review will help those responsible for developing and implementing IPE activities to make informed judgements in the use of facilitation approaches and techniques. In addition, this synthesis may provide useful information to staff/faculty developers in terms of possible identifying areas where professional development for both new and experienced IPE facilitators could be targeted.

\section{References}

Anderson ES, Thorpe LN. 2010. Interprofessional educator ambassadors: An empirical study of motivation and added value. Med Teach; 32(11):e492-500.

Atkins S, Lewin S, Smith H, Engel M, Fretheim A, Volmin J. 2008. Conducting a meta-ethnography of qualitative literature: Lessons learnt. BMC Med Res Method, 8:21 doi:10.1186/1471-2288-8-21

Barr H, Freeth D, Hammick M, Koppel I, Reeves S. 2005. Interprofessional education: Argument, assumption and evidence. (Oxford, Blackwell). 
Brandt B, Lutfiyya MN, King JA, Chioreso C. 2014. A scoping review of interprofessional collaborative practice and education using the lens of the Triple Aim. J Interprof Care; 28(5):393-9. doi: 10.3109/13561820.2014.906391

Britten N, Campbell R, Pope C, Donovan J, Morgan M, Pill R. 2002. Using meta ethnography to synthesise qualitative research: a worked example. J Health Serv Res \& Policy; 7(4):209-15.

Carlson E, Pilhammar E, \& Wann-Hansson C. 2011. The team builder: the role of nurses facilitating interprofessional student teams at a Swedish clinical training ward. Nurse Educ Pract; 11(5):30913.

Critical Appraisal Skills Programme. 2006. Making sense of evidence about clinical effectiveness: 10 questions to help you make sense of qualitative research. http://media.wix.com/ugd/dded87 29c5b002d99342f788c6ac670e49f274.pdf

Chipchase L, Allen S, Eley D, McAllister L, Strong J. 2012. Interprofessional supervision in an intercultural context: A qualitative study. J Interprof Care; 26(6):465-71.

Cleghorn G \& Baker G. 2000. What faculty need to learn about improvement and how to teach it to others. J Interprof Care; 14:147-59.

Clouder DL, Davies B, Sams M, McFarland L. 2012. "Understanding where you're coming from": discovering an [inter]professional identity through becoming a peer facilitator. J Interprof Care; 26(6):459-64. doi: 10.3109/13561820.2012.706335.

Cooper H \& Spencer-Dawe E. 2006. Involving service users in interprofessional education narrowing the gap between theory and practice. J Interprof Care; 20(6):603-17.

Curran V, Heath O, Adey T, Callahan T, Craig D, Hearn T, White H, Hollett A. 2012. An approach to integrating interprofessional education in collaborative mental health care. Acad psychiatry; 36(2):91-5.

Egan-Lee E, Baker L, Tobin S, Hollenberg E, Dematteo D, Reeves S. 2011. Neophyte facilitator experiences of interprofessional education: Implications for faculty development. J Interprof Care; 25(5):333-8.

Evans, S; Knight, T; Sønderlund, A; Tooley, G. 2014. Facilitators' experience of delivering asynchronous and synchronous online interprofessional education. Med Teach; 36(12):1051-6. 
Freeth D, Hammick M, Reeves S, Koppel I, Barr H. 2005. Effective Interprofessional Education: Development, Delivery \& Evaluation (Oxford, Blackwell).

Hammick M, Freeth D, Koppel I, Reeves S, Barr H. 2007. A best evidence systematic review of interprofessional education: BEME Guide no. 9. Med Teach; 29(8):735-51. doi:

$10.1080 / 01421590701682576$

Hancock B. 2002. Trent Focus for Research and Development in Primary Health Care: An Introduction to Qualitative Research. (Nottingham, University of Nottingham).

Hanna, E; Soren, B; Telner, D; MacNeill, H; Lowe, M; Reeves, S. 2013. Flying blind: the experience of online interprofessional facilitation. J Interprof Care; 27(4):298-304.

Holland K. 2002. Interprofessional education and practice: the role of the teacher/facilitator. Nurs Ed in Prac; 2: 221-222.

Howkins E \& Bray J. 2008. Through the PIPE. In Howkins E \& Bray J (eds) Preparing for Interprofessional Teaching: Theory and Practice. (Oxford, Radcliffe Publishing).

Jakobsen F \& Hansen J. 2014. Spreading the concept: An attempt to translate an interprofessional clinical placement across a Danish hospital. J Interprof Care; 28(5):407-12.

Lawlis TR, Anson J, Greenfield D. 2014. Barriers and enablers that influence sustainable interprofessional education: a literature review. J Interprof Care; 28(4):305-10.

Lindblom P, Scheja M, Torell E, Astrand P \& Fellander-Tsai L .2007. Learning orthopedics: Assessing medical students' experiences with interprofessional training in an orthopaedic clinical education ward. J Interprof Care; 21: 413-423.

Lindqvist SM \& Reeves S. 2007. Facilitators' perceptions of delivering interprofessional education: A qualitative study. Med Teach; 29(4):403-5.

Madden T, Graham A, Straussner A, Saunders LA, Schoener E, Henry R, Marcus MT, Brown RL. 2006. Interdisciplinary benefits in Project MAINSTREAM: A promising health professions educational model to address global substance abuse. J Interprof Care; 20: 655-664.

Noblit GW, Hare RD. 1988. Meta-Ethnography: Synthesising Qualitative Studies. (London, Sage).

Pauzé E, Reeves S. 2010. Examining the effects of interprofessional education on mental health providers: Findings from an updated systematic review. J Ment Health; 19(3):258-71. 
Rees D \& Johnson R. 2007. All together now? Staff views and experiences of a pre-qualifying interprofessional curriculum. J Interprof Care; 21(5):543-55

Reeves S. 2000. Community-based interprofessional education for medical, nursing and dental students. Health Social Care Comm; 8:269-76.

Reeves S. Fletcher S, Barr H, Birch I, Boet S, Davies N, McFadyen A, Rivera J, Kitto S. 2016. A BEME systematic review of the effects of interprofessional education: BEME Guide 39. Med Teach. [Epub ahead of print].

Reeves S, Goldman J, Burton A, Sawatzky-Girling B. 2010. Synthesis of systematic review evidence of interprofessional education. J Allied Health; 39 (Suppl 1):198-203

Reeves S, Pelone F, Hendry J, Lock N, Marshall J, Pillay L, Wood R. 2015. A meta-ethnography of the facilitation approaches employed in the delivery of interprofessional education within health and social care. Prospero Database. CRD42015017293. Available at: http://www.crd.york.ac.uk/PROSPERO/display record.asp?ID=CRD42015017293

Reeves S, Perrier L, Goldman J, Freeth D, Zwarenstein M. 2013. Interprofessional education: effects on professional practice and healthcare outcomes (update). Cochrane Database Syst Rev. CD002213. doi: 10.1002/14651858.CD002213.pub3.

Selle K, Salamon K, Boarman R \& Sauer J. 2008. Providing interprofessional learning through interdisciplinary collaboration: the role of "modeling". J Interprof Care; 22: 85-92.

Sockalingam S, Tan A, Hawa R, Pollex H, Abbey S, Hodges B. 2014. Interprofessional education for delirium care: a systematic review. J Interprof Care; 28(4):345-51.

Steinert Y. 2005. Learning together to teach together: Interprofessional education and faculty development. J Interprof Care; 19:60-75.

Sunguya BF, Hinthong W, Jimba M, Yasuoka J. 2014. Interprofessional education for whom? -challenges and lessons learned from its implementation in developed countries and their application to developing countries: a systematic review. PLoS One; 9(5):e96724.

Toye F, Seers K, Allcock N, Briggs M, Carr E, Barker K. 2014. Meta-ethnography 25 years on: challenges and insights for synthesising a large number of qualitative studies. BMC Med Res Methodol; 14:80. 
van Soeren M, Devlin-Cop S, MacMillan K, Baker L, Egan-Lee E, Reeves S. Simulated interprofessional education: An analysis of teaching and learning processes. J Interprof Care . 2011;25(6):434-40.

World Health Organization. 2010. Framework for Action on Interprofessional Education and Collaborative Practice. Geneva, Switzerland: World Health Organization. 
Figure 1 - Study identification flow chart
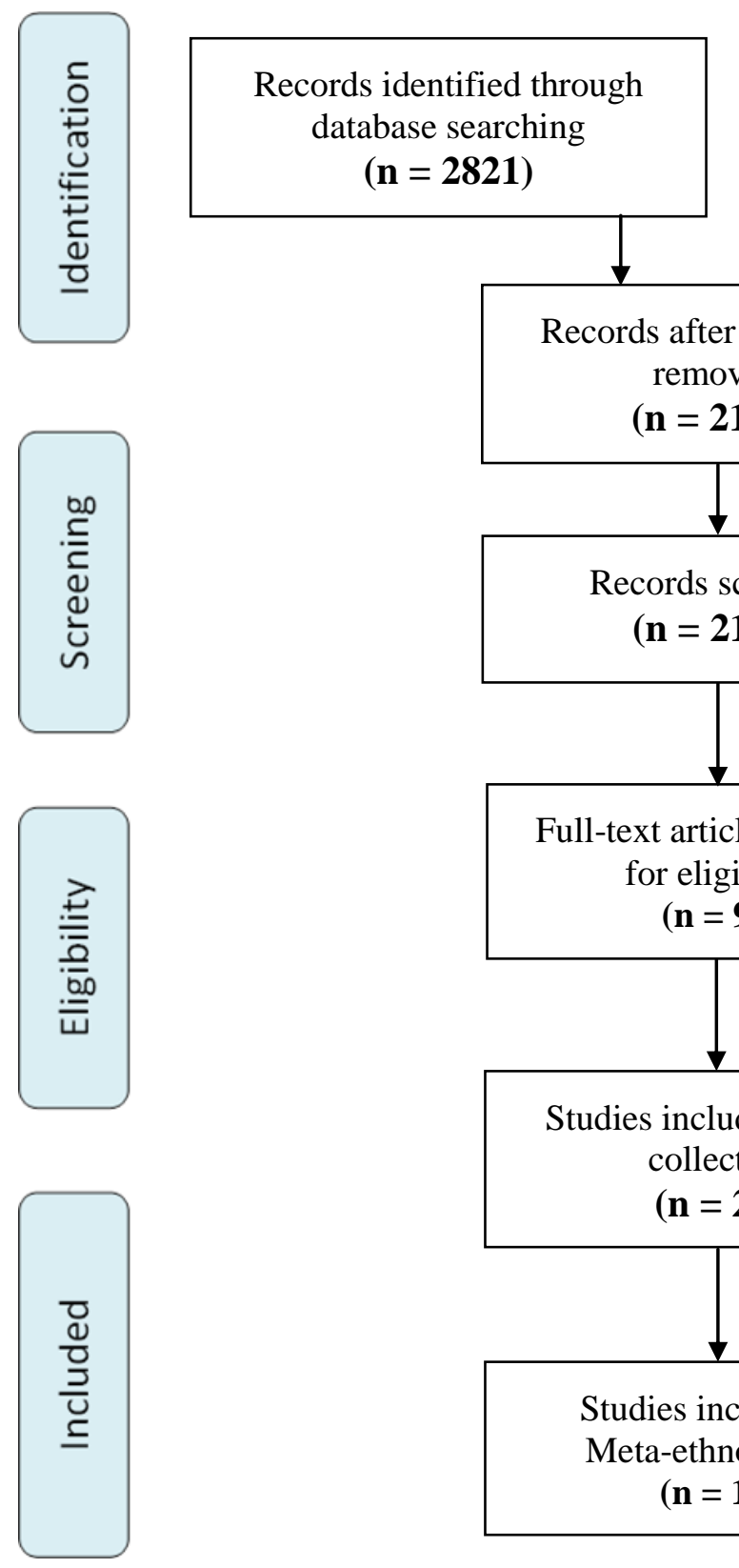

Additional records identified through other sources

$$
(\mathbf{n}=3)
$$

Records after duplicates removed

$(n=2164)$
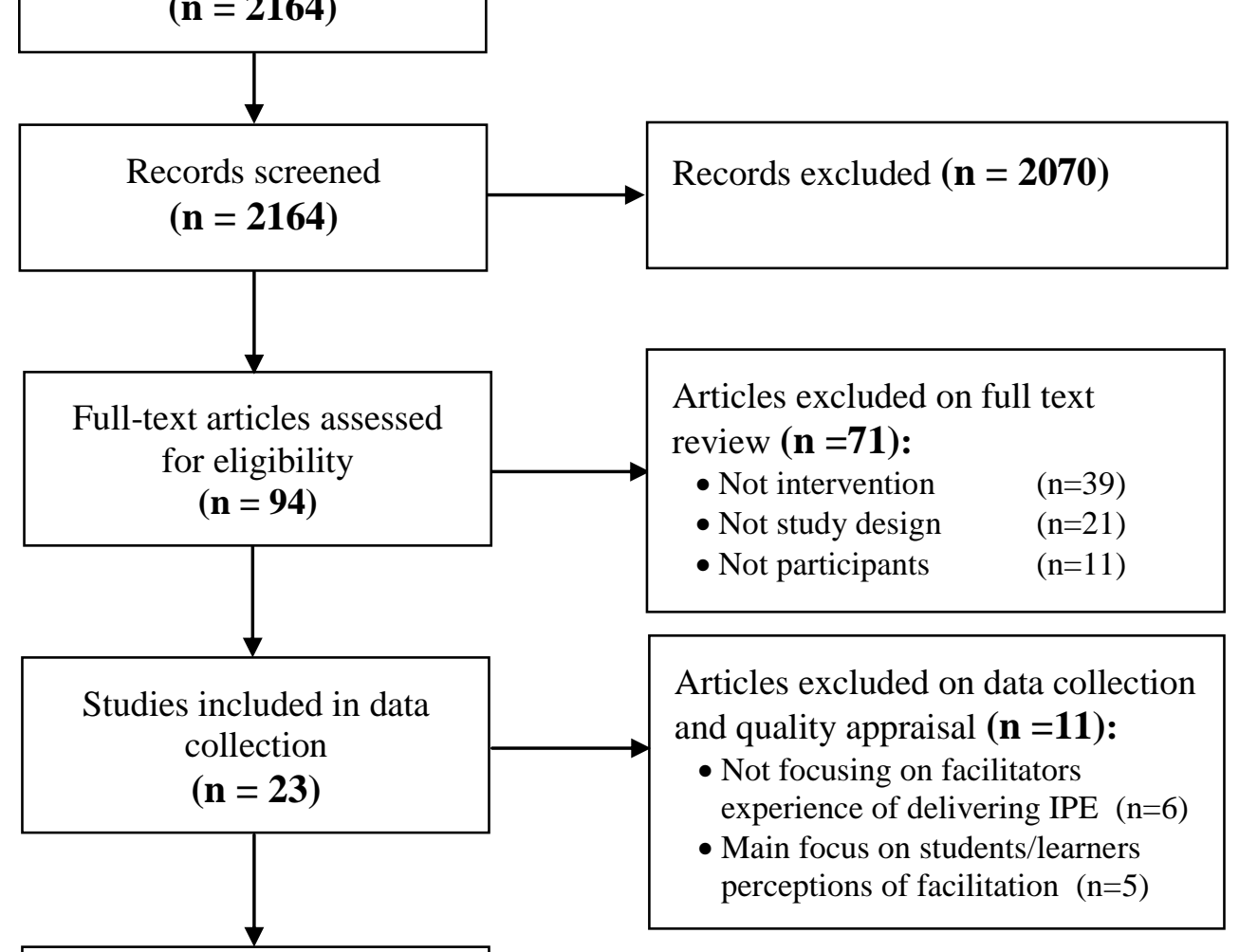

Studies included in

Meta-ethnography

$$
(\mathbf{n}=12)
$$


Table 1: Study characteristics

\begin{tabular}{|c|c|c|c|c|c|c|c|}
\hline \multicolumn{2}{|c|}{ Intervention } & \multirow[b]{2}{*}{ Aim(s)/research question(s) } & \multicolumn{2}{|c|}{ Methods } & \multirow[b]{2}{*}{$\begin{array}{l}\text { Participants } \\
\text { type (number) }\end{array}$} & \multirow[b]{2}{*}{ Country } & \multirow[b]{2}{*}{ Study } \\
\hline IPE type & $\begin{array}{l}\text { Facilitator } \\
\text { approach }\end{array}$ & & Study design & $\begin{array}{l}\text { Methods of data } \\
\text { collection }\end{array}$ & & & \\
\hline \multirow{4}{*}{$\begin{array}{l}\text { Classroom } \\
\text { based }\end{array}$} & $\begin{array}{l}\text { Single } \\
\text { facilitator }\end{array}$ & $\begin{array}{l}\text { "To investigate what key factors facilitators perceive as } \\
\text { important in allowing them to support the IPL process } \\
\text { in an effective manner" ( } p 403 \text { ) }\end{array}$ & $\begin{array}{l}\text { Single case } \\
\text { study }\end{array}$ & $\begin{array}{l}\text { Focus group, } \\
\text { Telephone interviews }\end{array}$ & $\begin{array}{l}\text { Medicine, nursing, speech and } \\
\text { language therapy, occupational } \\
\text { therapy and physiotherapy } \\
\text { (Total = 13) }\end{array}$ & UK & $\begin{array}{l}\text { Lindqvist \& } \\
\text { Reeves, } \\
2007\end{array}$ \\
\hline & $\begin{array}{c}\text { Single } \\
\text { facilitator }\end{array}$ & $\begin{array}{l}\text { "To establish an infrastructure for IPE and rigorously } \\
\text { evaluate both its outcomes and the process by which } \\
\text { such outcomes had transpired" ( } p \text { 503) }\end{array}$ & Phenomenology & $\begin{array}{l}\text { Focus group, } \\
\text { Individual interviews }\end{array}$ & $\begin{array}{l}\text { ‘Allied Health' (6); Nursing(4); } \\
\text { Policy studies (3); Maternal and } \\
\text { Child Health (1); Mental } \\
\text { Health/Learning Disabilities (1) } \\
\text { (Total = 15) }\end{array}$ & UK & $\begin{array}{l}\text { Rees \& } \\
\text { Johnston, } \\
\quad 2007\end{array}$ \\
\hline & $\begin{array}{l}\text { Co- } \\
\text { facilitation }\end{array}$ & $\begin{array}{l}\text { "To investigate the involvement of service users in the } \\
\text { delivery if IPE for undergraduate students" (p 605) }\end{array}$ & Case study & $\begin{array}{l}\text { Focus group, } \\
\text { Individual interviews, } \\
\text { written reflections }\end{array}$ & Not specified (Total = 7) & UK & $\begin{array}{l}\text { Cooper \& } \\
\text { Spencer- } \\
\text { Dawe, } \\
2006\end{array}$ \\
\hline & $\begin{array}{c}\text { Co- } \\
\text { facilitation }\end{array}$ & $\begin{array}{l}\text { "To evaluate whether the clinical tutors could create a } \\
\text { safe and challenging learning environment in another } \\
\text { setting to that of the ITU" ( } p \text { 407) }\end{array}$ & Case study & $\begin{array}{c}\text { Focus group, } \\
\text { Written reflections }\end{array}$ & $\begin{array}{l}\text { Nursing (4), Physiotherapy (2), } \\
\text { OT (2) (Total = 8) }\end{array}$ & Denmark & $\begin{array}{l}\text { Jakobsen \& } \\
\text { Hansen, } 2014\end{array}$ \\
\hline \multirow[t]{2}{*}{$\begin{array}{l}\text { Practice } \\
\text { based }\end{array}$} & $\begin{array}{l}\text { Clinical } \\
\text { supervision }\end{array}$ & $\begin{array}{c}\text { "To develop a detailed qualitative account of the views } \\
\text { of medical and allied health students, and their } \\
\text { supervisors in the context of an interprofessional } \\
\text { clinical placement" (p 466) }\end{array}$ & Case study & $\begin{array}{l}\text { Focus group, } \\
\text { Individual interviews }\end{array}$ & $\begin{array}{l}\text { Physiotherapy (2), OT (1), Speech } \\
\text { pathology (1) } \\
(\text { Total }=4)\end{array}$ & Vietnam & $\begin{array}{l}\text { Chipchase et } \\
\text { al., } 2012\end{array}$ \\
\hline & $\begin{array}{l}\text { Single } \\
\text { facilitator }\end{array}$ & $\begin{array}{l}\text { "To describe how nurses act when facilitating } \\
\text { interprofessional student teams at a clinical training } \\
\text { ward" ( } \mathrm{p} 310)\end{array}$ & Ethnography & $\begin{array}{l}\text { Focus group, } \\
\text { Individual interviews, } \\
\text { Observations }\end{array}$ & Nursing (Total = 8) & Sweden & $\begin{array}{l}\text { Carlson et al., } \\
2011\end{array}$ \\
\hline \multirow{2}{*}{$\begin{array}{l}\text { Classroom } \\
\text { and } \\
\text { Practice } \\
\text { based }\end{array}$} & $\begin{array}{l}\text { Single } \\
\text { facilitator }\end{array}$ & $\begin{array}{c}\text { To provide "...insight into their [neophyte facilitators] } \\
\text { perceptions and experiences in preparing for and } \\
\text { delivering IPE" ( } \mathrm{p} 333 \text { ) }\end{array}$ & $\begin{array}{l}\text { Multiple case } \\
\text { study }\end{array}$ & Individual interviews & $\begin{array}{l}\text { Nursing (8), Dietetics (3), } \\
\text { Medicine (3), OT (3), } \\
\text { Physiotherapy (3), Social work (3) } \\
\text { (Total }=21 \text { ) }\end{array}$ & Canada & $\begin{array}{l}\text { Egan-Lee et } \\
\text { al., } \\
2011\end{array}$ \\
\hline & $\begin{array}{l}\text { Co- } \\
\text { facilitation }\end{array}$ & $\begin{array}{c}\text { "To explore the impact of leading an IPE curriculum on } \\
\text { teachers, who were at the forefront of establishing a } \\
\text { new IPE curriculum ..." p 492) }\end{array}$ & Phenomenology & $\begin{array}{l}\text { Focus group, } \\
\text { Individual interviews }\end{array}$ & Not specified (Total = 58) & UK & $\begin{array}{l}\text { Anderson \& } \\
\text { Thorpe, } 2010\end{array}$ \\
\hline
\end{tabular}




\begin{tabular}{|c|c|c|c|c|c|c|c|}
\hline & & & & & (Total $=19)$ & & \\
\hline & $\begin{array}{c}\text { Co- } \\
\text { facilitation }\end{array}$ & $\begin{array}{l}\text { "What is the experience of IPE facilitators in the online } \\
\text { environment and what supports are most useful" } \\
\text { (p 299) }\end{array}$ & Case study & $\begin{array}{l}\text { Focus group, } \\
\text { Individual interviews, } \\
\text { Observations }\end{array}$ & $\begin{array}{c}\text { Nursing (2), Dental Hygiene (1), } \\
\text { Medicine (1), Pharmacy (1), } \\
\text { Physiotherapy (1), Social work (1) } \\
\text { (Total = 7) }\end{array}$ & Canada & $\begin{array}{c}\text { Hanna et al., } \\
2013\end{array}$ \\
\hline & $\begin{array}{c}\text { Peer } \\
\text { facilitation }\end{array}$ & $\begin{array}{l}\text { "..To explore the range of cognitive, personal and } \\
\text { instrumental gains for peer facilitators in the online } \\
\text { IPLP..." (p 461) }\end{array}$ & $\begin{array}{l}\text { Participatory } \\
\text { action research }\end{array}$ & $\begin{array}{l}\text { Individual interviews, } \\
\text { written reflections }\end{array}$ & Not specified (Total $=8$ ) & UK & $\begin{array}{c}\text { Clouder et al., } \\
2012\end{array}$ \\
\hline Simulation & $\begin{array}{c}\text { Co- } \\
\text { facilitation }\end{array}$ & $\begin{array}{l}\text { To examine "the nature and complexity of } \\
\text { interprofessional processes as they are undertaken } \\
\text { within a simulated learning context" (p 433) }\end{array}$ & Case study & $\begin{array}{l}\text { Observations, } \\
\text { Focus group }\end{array}$ & $\begin{array}{l}\text { Lead facilitators (2), Clinical site } \\
\text { facilitators }(7) \\
\text { (Total }=9)\end{array}$ & Canada & $\begin{array}{c}\text { van Soeren et } \\
\text { al., } 2011\end{array}$ \\
\hline
\end{tabular}


Table 2: Quality criteria and results

\begin{tabular}{|c|c|c|c|c|c|c|c|c|c|c|c|c|c|}
\hline & Quality criteria & 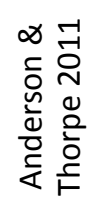 & 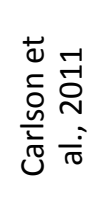 & 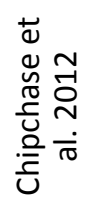 & 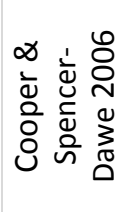 & 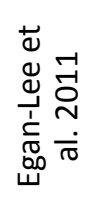 & 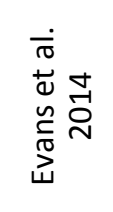 & 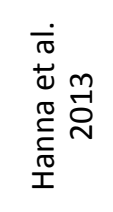 & 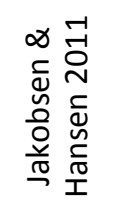 & 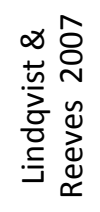 & 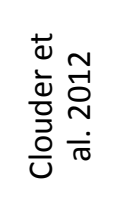 & 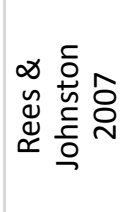 & 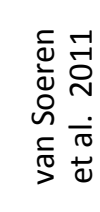 \\
\hline 1 & $\begin{array}{l}\text { Was there a clear statement of the aims of } \\
\text { the research? }\end{array}$ & Yes & Yes & Yes & Yes & Yes & Yes & Yes & Yes & Yes & Yes & Yes & Yes \\
\hline 2 & Is a qualitative methodology appropriate? & Yes & Yes & Yes & Yes & Yes & Yes & Yes & Yes & Yes & Yes & Yes & Yes \\
\hline 3 & $\begin{array}{l}\text { Was the research design appropriate to } \\
\text { address the aims of the research? }\end{array}$ & Yes & Yes & Yes & Yes & Yes & Yes & Yes & Yes & Yes & Yes & Yes & Yes \\
\hline 4 & $\begin{array}{l}\text { Was the recruitment strategy appropriate to } \\
\text { the aims of the research? }\end{array}$ & Yes & Yes & $\begin{array}{l}\text { Not } \\
\text { clear }\end{array}$ & $\begin{array}{l}\text { Not } \\
\text { clear }\end{array}$ & Yes & Yes & Yes & $\begin{array}{l}\text { Not } \\
\text { clear }\end{array}$ & Yes & No & $\begin{array}{l}\text { Not } \\
\text { clear }\end{array}$ & $\begin{array}{l}\text { Not } \\
\text { clear }\end{array}$ \\
\hline 5 & $\begin{array}{l}\text { Was the data collected in a way that } \\
\text { addressed the research issue? }\end{array}$ & Yes & Yes & Yes & Yes & Yes & Yes & Yes & Yes & Yes & Yes & Yes & Yes \\
\hline 6 & $\begin{array}{l}\text { Has the relationship between researcher and } \\
\text { participants been adequately considered? }\end{array}$ & No & Yes & No & No & Yes & $\begin{array}{l}\text { Not } \\
\text { clear }\end{array}$ & $\begin{array}{l}\text { Not } \\
\text { clear }\end{array}$ & $\begin{array}{l}\text { Not } \\
\text { clear }\end{array}$ & No & $\begin{array}{l}\text { Not } \\
\text { clear }\end{array}$ & Yes & No \\
\hline 7 & $\begin{array}{l}\text { Have ethical issues been taken into } \\
\text { consideration? }\end{array}$ & Yes & Yes & Yes & Yes & Yes & Yes & Yes & Yes & Yes & Yes & Yes & Yes \\
\hline 8 & Was the data analysis sufficiently rigorous? & Yes & Yes & Yes & Yes & Yes & Yes & Yes & Yes & Yes & Yes & Yes & Yes \\
\hline 9 & Is there a clear statement of findings? & Yes & Yes & Yes & Yes & Yes & Yes & Yes & Yes & Yes & Yes & Yes & Yes \\
\hline 10 & How rigorous is the research? & + & ++ & + & + & ++ & ++ & + & + & ++ & + & ++ & ++ \\
\hline
\end{tabular}

Note: + + = 'high rigor'; + = 'good rigor' 
Table 3: Key synthesis findings

\begin{tabular}{|c|c|c|}
\hline Concepts & Second order interpretations & Third order interpretations \\
\hline $\begin{array}{l}\text { Logistical and organisational } \\
\text { issues that affect facilitators' } \\
\text { work }\end{array}$ & $\begin{array}{l}\text { "Many educators were teaching over and above their allotted timetables and a lack of resources and support with operational } \\
\text { issues was evident" (Anderson \& Thorpe., 2010; p. 499). } \\
\text { Some facilitators were working in part-time or full-time clinical positions and were able to undertake their facilitation role } \\
\text { outside of their normal working hours" (Evans et al., 2014; p. 1054). } \\
\text { "[large cohorts of students] create significant difficulties which impact on staff engagement with IPE" (Rees \& Johnson., 2007; p. } \\
552 \text { ). } \\
\text { "Facilitators enjoyed the flexibility of the facilitation role and more specifically, the fact that the asynchronous aspect of their role } \\
\text { could be fitted around other important aspects of their lives (Evans et al., 2014; p. 1054). }\end{array}$ & $\begin{array}{l}\text { The effect of contextual } \\
\text { characteristics on } \\
\text { facilitation }\end{array}$ \\
\hline $\begin{array}{l}\text { The influence of technology } \\
\text { on facilitation }\end{array}$ & $\begin{array}{l}\text { "Even when technology worked smoothly, facilitators were acutely aware of the huge reduction in the non-verbal cues } \\
\text { facilitators and participants use to communicate" (Hanna et al., 2013; p. 300). } \\
\text { "Several facilitators described using the technological problems as a learning experience for the students. These facilitators } \\
\text { talked about encouraging their student teams to problem solve solutions as to how they might involve team members that were } \\
\text { having technological difficulties" (Evans et al., 2014; p. 1054). } \\
\text { "Technological problems in the synchronous environment over time"; "Delayed group formation appeared to be associated with } \\
\text { reduced interprofessional collaboration" (Hanna et al., 2013; p. 301). } \\
\text { "Facilitators also mentioned that at times it was difficult to engage some students in the synchronous environment due to a lack } \\
\text { of body language cues that are present in the face to face environment". (Evans et al., 2014; p. 1055). }\end{array}$ & \\
\hline $\begin{array}{l}\text { The need for preparation and } \\
\text { support }\end{array}$ & $\begin{array}{l}\text { "Existing staff development opportunities must be well planned and publicised in order to reassure facilitators and those } \\
\text { contemplating the role, that adequate support is available and that opportunities exist for sharing knowledge, experiences and } \\
\text { ideas" (Rees and Johnson., 2007; p. 553). } \\
\text { "It was felt that the induction allowed facilitators to learn the basic principles of IPL" (Lindqvist \& Reeves., 2007; p. 404). } \\
\text { "As many of the facilitators had limited experience [...] they emphasized the overall importance of facilitator support" (Evans et } \\
\text { al., 2014; p. 1054). } \\
\text { "The [interprofessional] competencies of the clinical tutors must be continually trained and maintained (Jakobsen \& Hansen., } \\
\text { 2014; p. 411). } \\
\text { "An important factor to consider in the preparation of IPE facilitators is an understanding of the complexities of facilitating } \\
\text { different groups of professions due to heterogeneous learning needs as well as histories of interprofessional friction and issues } \\
\text { relating to imbalances of power, status and authority" (Egan-Lee et al., 2011; p. 337). } \\
\text { "It was felt that the weekly de-briefing sessions encouraged the facilitators to share experiences and obtain support from one } \\
\text { another" (Lindqvist \& Reeves., 2007; p. 404). }\end{array}$ & $\begin{array}{l}\text { How facilitator experience } \\
\text { influence their facilitation } \\
\text { work }\end{array}$ \\
\hline
\end{tabular}




\begin{tabular}{|c|c|c|}
\hline $\begin{array}{l}\text { Collaborating and co- } \\
\text { facilitating }\end{array}$ & $\begin{array}{l}\text { "Analysis of the data supported the enhanced value of co-facilitation to enable collaborative online learning in IPE" (Hanna et al., } \\
\text { 2013; p. 301). } \\
\text { "The presence of more than one facilitator from different professional backgrounds helped connect different learners' } \\
\text { experiences [and] capture more learning opportunities" (van Soeren et al., 2011; p. 438). } \\
\text { "Forms of support could include co-facilitation opportunities for neophyte and experienced IPE facilitators. In such instances, } \\
\text { new facilitators would have the opportunity to observe, mirror facilitation styles, and receive feedback" (Egan-Lee et al., 2011; p. } \\
\text { 355). } \\
\text { "For many educators team-teaching, or paired facilitation, enabled the observation of colleagues while teaching". (Anderson \& } \\
\text { Thorpe., 2010; p. 497). } \\
\text { "All the facilitators had found the experience of working with service users [as co-facilitators] positive and enjoyable, } \\
\text { acknowledging the educational value of the programme" (Cooper and Spencer-Dawe., 2006; p. 611). } \\
\text { "A positive side effect of common planning and collaboration was that the tutors got to know each other better individually and } \\
\text { professionally, thus enhancing future formal and informal collaboration concerning students' clinical learning" (Jakobsen \& } \\
\text { Hansen., 2014; p. 410). }\end{array}$ & \\
\hline $\begin{array}{l}\text { IPE facilitation as a } \\
\text { professional development } \\
\text { opportunity }\end{array}$ & $\begin{array}{l}\text { "The facilitators saw the [facilitation] experience as an opportunity for their development of skills as a facilitator of learning, as } \\
\text { an IPE facilitator and as an online facilitator" (Evans et al., 2014; p. 1053). } \\
\text { "Facilitators acknowledged increased understanding of other professions [they] developed skills in organisation, communication, } \\
\text { teaching, diplomacy, conflict resolution" (Clouder et al., 2012; p. 462). } \\
\text { "Many facilitators noted that their facilitation experiences contributed to improvements in their knowledge of interprofessional } \\
\text { concepts and approaches" (Egan-Lee et al., 2011; p. 336). } \\
\text { "Leading the IPE curriculum had brought these educators together in the design and delivery of the curriculum and this has } \\
\text { enabled them to further their knowledge of each other's professions" (Anderson \& Thorpe., 2010; p. 496). } \\
\text { "On a personal level, facilitators felt they had gained a valuable learning experience from working with service users in delivering } \\
\text { IPE. Following their experiences, they described a number of changes they had made to their own clinical and professional } \\
\text { practice to make service users more central to their work" (Cooper \& Spencer-Dawe., 2006; p. 612). } \\
\text { "Perceiving that the students were learning was personally satisfying for the facilitators, as they felt they had assisted that } \\
\text { process through their facilitating roles" (Evans et al., 2014; p. 1053). } \\
\text { "The opportunity to form new relationships with colleagues and students from other disciplines [was a key benefit of IPE } \\
\text { facilitation]. In particular the associations with other professional colleagues had enhanced [facilitators' own] practice" } \\
\text { (Anderson \& Thorpe., 2010; p. 498). }\end{array}$ & \\
\hline $\begin{array}{l}\text { Employing differing } \\
\text { approaches to } \\
\text { interprofessional teaching }\end{array}$ & $\begin{array}{l}\text { "Facilitators adopted one of two contrasting approaches which contributed to how they facilitated the debrief session. One } \\
\text { approach seemed more 'learner-centric', while the other approach appeared to be more 'teacher-centric' in nature. These } \\
\text { differing approaches resulted in contrasting types of interprofessional discussion amongst the learners" (van Soeren et al., 2011; } \\
\text { p. 438). } \\
\text { Facilitators employed "a reflective approach [...] as a conscious educational strategy with the intention to let students explore }\end{array}$ & $\begin{array}{l}\text { Need to use a range of } \\
\text { strategies for effective } \\
\text { facilitation }\end{array}$ \\
\hline
\end{tabular}




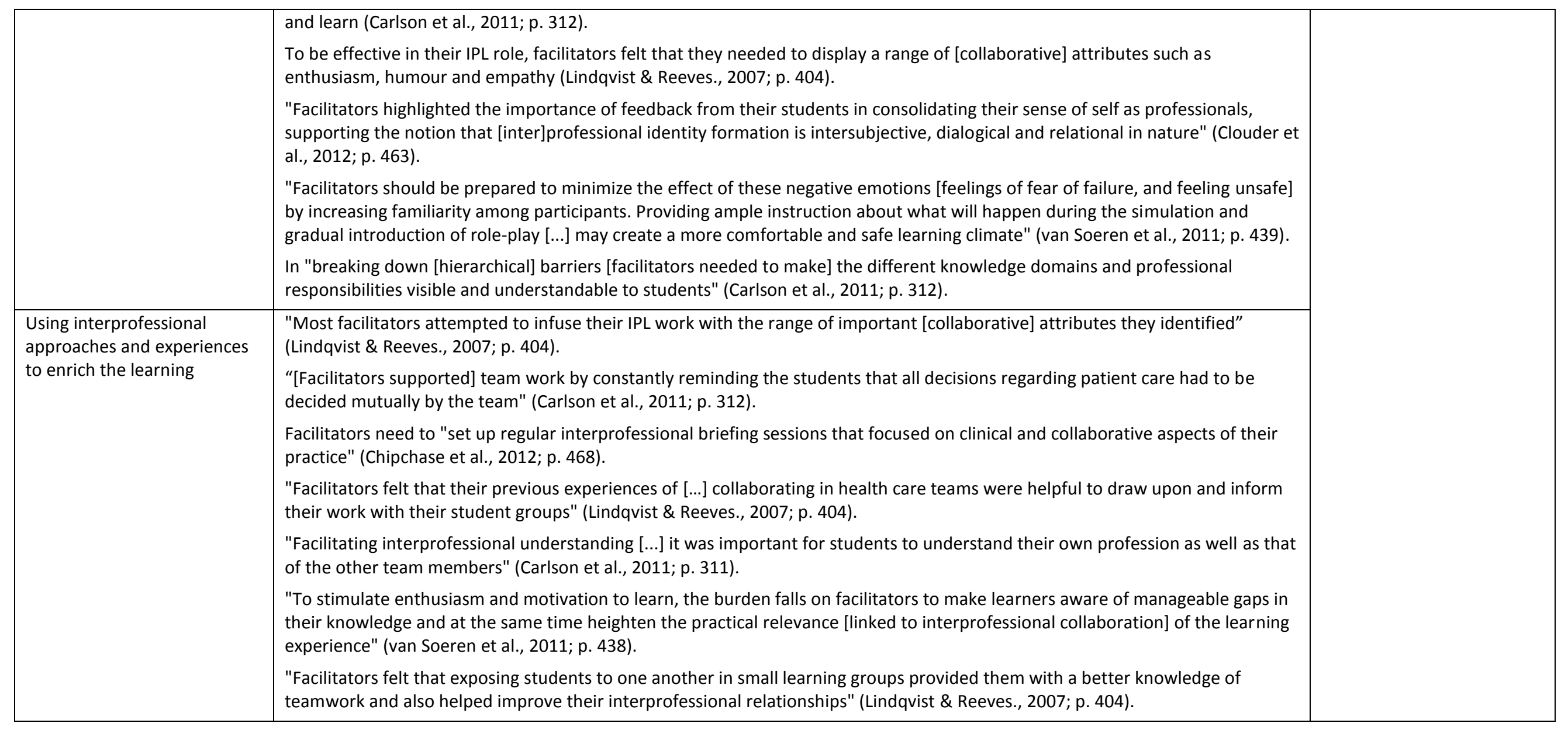

